\title{
JBIR-120: a new growth inhibitor of hormone-refractory prostate cancer cells
}

\author{
Teppei Kawahara ${ }^{1}$, Takahiro Hosoya $^{1}$, Masao Tsukamoto ${ }^{1}$, Sachiko Okabe ${ }^{2}$, Hideki Yamamura ${ }^{3}$, \\ Masayuki Hayakawa ${ }^{3}$, Hiroyuki Seimiya ${ }^{2}$, Motoki Takagi ${ }^{1}$ and Kazuo Shin-ya ${ }^{4}$
}

The Journal of Antibiotics (2012) 65, 373-375; doi:10.1038/ja.2012.32; published online 25 April 2012

Keywords: androgen; anti-cancer; lichen; prostate cancer; Streptomyces

Prostate cancer is a common nondermatological cancer in older adult men. Androgen receptor (AR) signaling has a central role in prostate cancer cell growth and survival, ${ }^{1}$ and therefore, androgen ablation therapy is recognized as a standard regimen for the treatment of advanced and metastatic prostate cancers. ${ }^{2}$ However, most patients who undergo androgen ablation progress from being androgendependent to developing hormone-refractory prostate cancer within 2 years after initiating therapy. Although the recurrent tumors are often resistant to standard AR-targeting agents, which cause deprivation of androgens or block androgen-AR interaction, AR-mediated signaling still has a key role in the development and maintenance of hormone-refractory prostate cancers. ${ }^{3-5}$ Thus, identifying new therapeutic agents targeting the AR signaling pathway may possibly control the occurrence of hormone-refractory prostate cancers. Mashima et al. ${ }^{6}$ earlier reported that nigericin can block AR-mediated signaling in hormone-refractory prostate cancer cells. In the current study, we discovered a novel compound-JBIR-120 (1) - extracted from the culture broth of a new Streptomyces strain, RI104-LiC104. This paper describes the isolation, structure elucidation and biological activity of $\mathbf{1}$.

Streptomyces strain RI104-LiC104 was isolated from a lichen obtained from the Rishiri Island, Hokkaido Prefecture, Japan, by using the moist incubation and desiccation method. ${ }^{7}$ To identify the strain, the 16S rRNA gene sequence of RI104-LiC106 was determined (DDBJ accession number, AB693145) and compared with sequences in the Eztaxon-type strain database. ${ }^{8}$ Sequence analysis showed that the strain suspected as a new species of the genus Streptomyces.

The strain was cultivated in $50-\mathrm{ml}$ test tubes containing $15 \mathrm{ml}$ of a seed medium consisting of $1.0 \%$ starch (Kosokagaku, Tokyo, Japan), $1.0 \%$ polypeptone (Nihon Pharmaceutical, Tokyo, Japan),
1.0\% molasses (Dai-Nippon Meiji Sugar, Tokyo, Japan) and 1.0\% meat extract (Extract Ehlrich; Wako Pure Chemical Industry, Osaka, Japan) at $\mathrm{pH} 7.2$ (adjusted before sterilization). The test tubes were maintained on a reciprocal shaker (320 r.p.m.) at $27^{\circ} \mathrm{C}$ for 2 days. Aliquots $(2.5 \mathrm{ml}$ each) of the broth were transferred to $500-\mathrm{ml}$ baffled Erlenmeyer flasks containing $100 \mathrm{ml}$ of a production medium consisting of $2.0 \%$ glycerol (Nacalai Tesque, Kyoto, Japan), 1.0\% molasses (Dai-Nippon Meiji Sugar), $0.5 \%$ casein (Kanto Chemical, Tokyo, Japan), $0.1 \%$ polypeptone (Nihon Pharmaceutical) and $0.4 \% \mathrm{CaCO}_{3}$ (Kozaki Pharmaceutical, Tokyo, Japan) at pH 7.2 (adjusted before sterilization), and cultured on a rotary shaker ( 180 r.p.m.) at $27^{\circ} \mathrm{C}$ for 5 days.

The fermentation broth (2l) was separated by centrifugation. The supernatant was extracted using EtOAc $(1.81 \times 3)$. The mycelial cake was extracted using acetone $(600 \mathrm{ml})$ and filtered, and the filtrate was concentrated in vacuo. The residual aqueous concentrate $(80 \mathrm{ml})$ was partitioned between EtOAc and $\mathrm{H}_{2} \mathrm{O}$ (equal volume $\times 3$ ). After drying with $\mathrm{Na}_{2} \mathrm{SO}_{4}$, both EtOAc layers were combined and evaporated in vacuo. The residue $(808 \mathrm{mg}$ ) was subjected to normal-phase medium-pressure liquid chromatography (Purif-Pack SI-30; Shoko Scientific, Yokohama, Japan) and successively developed using a gradient system of $n$-hexane-EtOAc (0-15\% EtOAc), followed by the stepwise solvent system of $\mathrm{CHCl}_{3}-\mathrm{MeOH}(0,2,5,10,20,30$ and $100 \% \mathrm{MeOH}$ ). The $5 \% \mathrm{MeOH}$-eluted fraction (27 mg) was applied to reversed-phase medium-pressure liquid chromatography (Purif-Pack ODS-30; Shoko Scientific) by using an $\mathrm{H}_{2} \mathrm{O}-\mathrm{MeOH}$ stepwise solvent system $(30,50,60,70,80$ and $90 \% \mathrm{MeOH})$. The $70 \% \mathrm{MeOH}$ fraction was evaporated in vacuo to obtain $\mathbf{1}(2.8 \mathrm{mg})$ as a colorless amorphous product.

The molecular formula of $\mathbf{1}$ was determined as $\mathrm{C}_{18} \mathrm{H}_{18} \mathrm{~N}_{2} \mathrm{O}_{3}$ through high-resolution ESI MS $\left(\mathrm{m} / z 309.1237[\mathrm{M}-\mathrm{H}]^{-}\right.$; calcd.

\footnotetext{
1Biomedicinal Information Research Center (BIRC), Japan Biological Informatics Consortium (JBIC), Koto-ku, Tokyo, Japan; ${ }^{2}$ Division of Molecular Biotherapy, Cancer Chemotherapy Center, Japanese Foundation for Cancer Research, Koto-ku, Tokyo, Japan; 3 Interdisciplinary Graduate School of Medicine and Engineering, University of Yamanashi, Kofu, Japan and ${ }^{4}$ Biomedicinal Information Research Center (BIRC), National Institute of Advanced Industrial Science, and Technology (AIST), Koto-ku, Tokyo, Japan.

Correspondence: Dr K Shin-ya, Biomedicinal Information Research Centre (BIRC), National Institute of Advanced Industrial Science and Technology (AIST), 2-4-7 Aomi, Koto-ku, Tokyo 135-0064, Japan.

E-mail: k-shinya@aist.go.jp or

Dr M Takagi, Biomedicinal Information Research Centre (BIRC), Japan Biological Informatics Consortium (JBIC), 2-4-7 Aomi, Koto-ku, Tokyo 135-0064, Japan. E-mail: motoki-takagi@aist.go.jp
}

Received 27 February 2012; revised 14 March 2012; accepted 16 March 2012; published online 25 April 2012 
309.1239). The optical rotation was $[\alpha]_{\mathrm{D}}^{25}-10.5$ (c 0.12, in $\mathrm{MeOH}$ ), and the UV spectrum showed maximal absorptions at $249(\varepsilon, 6400)$, $304(\varepsilon, 3500)$ and $342(\varepsilon, 3700) \mathrm{nm}$ in $\mathrm{MeOH}$. The IR absorptions (attenuated total reflectance) at 3470,1714 and $1670 \mathrm{~cm}^{-1}$ showed the presence of hydroxy, carbonyl and imino groups, respectively. The planar structure was clarified by a series of 2D NMR analyses, including double quantum-filtered COSY, heteronuclear singlequantum coherence and constant-time $\mathrm{HMBC}^{9}$ spectra. The ${ }^{13} \mathrm{C}$ and ${ }^{1} \mathrm{H}$ NMR data for $\mathbf{1}$ are listed in Table 1.

The sequence from an aromatic methine proton $3^{\prime}-\mathrm{H}\left(\delta_{\mathrm{H}} 6.31\right)$ to an ortho- and meta-coupled aromatic methine proton $6^{\prime}-\mathrm{H}\left(\delta_{\mathrm{H}} 7.93\right.$; $J=1.8,8.4 \mathrm{~Hz})$ through aromatic methine protons $4^{\prime}-\mathrm{H}\left(\delta_{\mathrm{H}} 7.14\right)$ and $5^{\prime}-\mathrm{H} \quad\left(\delta_{\mathrm{H}}\right.$ 6.54) observed in the double quantum-filtered COSY spectrum showed the presence of a 1,2-disubstituted benzene ring. Strong couplings from $4^{\prime}-\mathrm{H}$ and $6^{\prime}-\mathrm{H}$ to an aromatic quaternary carbon $\mathrm{C}-2^{\prime}\left(\delta_{\mathrm{C}} 150.5\right)$, and from $3^{\prime}-\mathrm{H}$ and $5^{\prime}-\mathrm{H}$ to another aromatic quaternary carbon $\mathrm{C}-1^{\prime}\left(\delta_{\mathrm{C}} 111.0\right)$ established the assignments of the benzene ring moiety. Additional $\mathrm{HMBC}$ from $6^{\prime}-\mathrm{H}$ to a carbonyl carbon $\mathrm{C}-7^{\prime}\left(\delta_{\mathrm{C}} 171.3\right)$ and the molecular formula of $\mathbf{1}$ (vide infra) revealed that a carboxylic acid functional group is substituted at position $\mathrm{C}-1^{\prime}$.

The sequence from terminal methyl protons $10-\mathrm{H}_{3}\left(\delta_{\mathrm{H}} 1.07\right)$ to a low-field-shifted $s p^{3}$ methine proton $8-\mathrm{H}\left(\delta_{\mathrm{H}}\right.$ 5.48) through the aliphatic methylene protons $9-\mathrm{H}_{2}\left(\delta_{\mathrm{H}} 1.91 ; 1.84\right)$ established a propyl unit. ${ }^{1} \mathrm{H}-{ }^{13} \mathrm{C}$ long-range couplings from $8-\mathrm{H}$ to $\mathrm{C}-2$ ', together with the ${ }^{13} \mathrm{C}$ chemical shift value at $\mathrm{C}-8\left(\delta_{\mathrm{C}} 51.7\right)$, proved that the propyl and the benzene ring moieties were joined by a nitrogen atom. Furthermore, $\mathrm{HMBC}$ correlations from $8-\mathrm{H}$ to aromatic quaternary carbons $\mathrm{C}-7 \mathrm{a}\left(\delta_{\mathrm{C}} 140.3\right), \mathrm{C}-7\left(\delta_{\mathrm{C}} 139.0\right)$, and an aromatic methine carbon $\mathrm{C}-6\left(\delta_{\mathrm{C}} 146.1\right)$, established the relationships of these carbons. Strong couplings from the aromatic methine protons $6-\mathrm{H}\left(\delta_{\mathrm{H}} 8.58\right)$ and $4-\mathrm{H}\left(\delta_{\mathrm{H}} 8.72\right)$ to the aromatic carbon $\mathrm{C}-7$ a elucidated their positions and assignments, as shown in Figure 1b.

A spin coupling between methylene protons $2-\mathrm{H}_{2}\left(\delta_{\mathrm{H}} 2.83,2 \mathrm{H}\right)$ and $3-\mathrm{H}_{2}\left(\delta_{\mathrm{H}} 3.26,2 \mathrm{H}\right)$ were also observed. On the basis of the $\mathrm{HMBC}$ correlations from $2-\mathrm{H}$ and $3-\mathrm{H}$ to an $\alpha, \beta$-unsaturated ketone carbonyl carbon $\mathrm{C}-1\left(\delta_{\mathrm{C}} 208.5\right)$, aromatic quaternary carbons $\mathrm{C}-3 \mathrm{a}$

Table $1{ }^{13} \mathrm{C}$ and ${ }^{1}$ HNMR spectroscopic data for JBIR-120 (1)

\begin{tabular}{|c|c|c|}
\hline Position & ${ }^{13} \mathrm{C}$ & ${ }^{1} \mathrm{H}(\mathrm{J}$ in $\mathrm{Hz})$ \\
\hline 1 & 208.5 & \\
\hline 2 & 36.8 & 2.83, ddd $(5.4,6.0,10.5)$ \\
\hline 3 & 23.7 & $3.26, \mathrm{dd}(5.4,6.0)$ \\
\hline $3 a$ & 149.3 & \\
\hline 4 & 148.2 & $8.72, \mathrm{~s}$ \\
\hline 6 & 146.1 & $8.58, \mathrm{~s}$ \\
\hline 7 & 139.0 & \\
\hline $7 a$ & 140.3 & \\
\hline 8 & 51.7 & $5.48, \mathrm{dd}(4.8,7.2)$ \\
\hline 9 & 31.1 & $1.91, \mathrm{ddq}(4.8,7.8,15.0) ; 1.84, \mathrm{ddq}(7.2,7.8,15.0)$ \\
\hline 10 & 10.9 & $1.07, \mathrm{t}(7.8)$ \\
\hline $1^{\prime}$ & 111.0 & \\
\hline $2^{\prime}$ & 150.5 & \\
\hline $3^{\prime}$ & 112.2 & $6.31, \mathrm{~d}(9.0)$ \\
\hline $4^{\prime}$ & 134.8 & $7.14, \mathrm{ddd}(1.8,9.0,9.0)$ \\
\hline $5^{\prime}$ & 115.4 & $6.54, \mathrm{dd}(8.4,9.0)$ \\
\hline $6^{\prime}$ & 132.7 & $7.93, \mathrm{dd}(1.8,8.4)$ \\
\hline $7^{\prime}$ & 171.3 & \\
\hline
\end{tabular}

${ }^{13} \mathrm{C}(150 \mathrm{MHz})$ and ${ }^{1} \mathrm{H}(600 \mathrm{MHz}) \mathrm{NMR}$ spectra were taken by $600 \mathrm{NB}$ CL NMR System (Varian, Palo Alto, $\mathrm{CA}, \mathrm{USA})$ in $\mathrm{CHCl}_{3}-d / \mathrm{CH}_{3} \mathrm{OH}-d_{4}(1: 1)$, and the solvent peak was used as an internal standard $\left(\delta_{\mathrm{C}} 49.0, \delta_{\mathrm{H}} 3.35\right.$ p.p.m.).
$\left(\delta_{\mathrm{C}}\right.$ 149.3) and C-7a were shown to consist of a 5-membered ring system. According to the molecular formula and unsaturated number, the sequence from C-3a to C-7a forms a pyridine moiety, whereas C-7' consists of a carboxylic-acid functional group. These results indicated the presence of a 6,7-dihydro- $5 \mathrm{H}$-cyclopenta $[c]$ pyridin-5one moiety, with $\mathrm{C}-8$ attached to $\mathrm{C}-7$. By taking into consideration these results, the gross structure of $\mathbf{1}$ is shown in Figure 1. Compound 1 is the first example of a louisianin- and ulupyrinone-type compound containing 2 -aminobenzoic acid. ${ }^{10,11}$

We evaluated the inhibitory effect of $\mathbf{1}$ on the growth of the AR-positive human prostate cancer cell line, $22 \mathrm{Rv} 1,{ }^{12}$ which is known to be involved with AR signaling. Cell growth with or without androgen (dihydrotestosterone) was examined. The cells were treated with 0 and $80 \mu \mathrm{M}$ of 1 in the presence or absence of $10 \mathrm{~nm}$ dihydrotestosterone for 5 days, and the cell growth was measured by a WST-8 colorimetric assay (Cell Counting Kit; Dojindo, Kumamoto, Japan). Compound $\mathbf{1}$ showed weak cytotoxicity against 22Rv1 cells $\left(\mathrm{IC}_{50}=150 \mu \mathrm{M}\right)$. Rather, 1 effectively suppressed the cell growth activated by dihydrotestosterone, which shows 2.7 -fold rise compared with dihydrotestosterone-depleted condition (Figure 2).
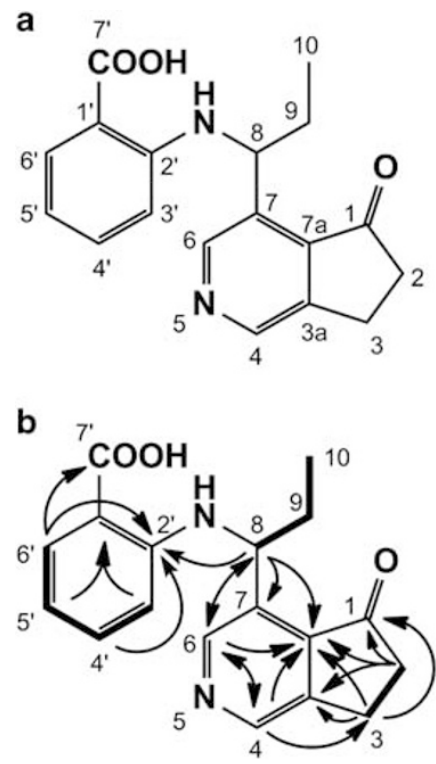

Figure 1 (a) Structure of JBIR-120 (1). (b) Key correlations of double quantum-filtered COSY (bold lines) and CT-HMBC (arrows) spectra of 1.

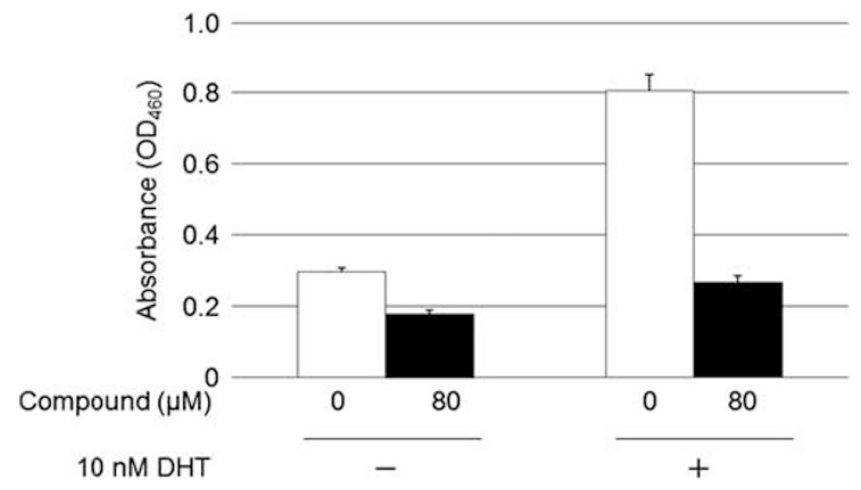

Figure 2 Inhibitory effect of $\mathbf{1}$ on the growth of AR-positive human prostate cancer cells activated by AR signaling (DHT: dihydrotestosterone). 
These results indicate that $\mathbf{1}$ inhibits androgen-dependent growth of the prostate cancer cells. Louisianin A, which is the analog of $\mathbf{1}$, has been reported to show growth inhibition in AR-positive SC 115 cells in the presence of testosterone. ${ }^{13}$ The results of our study showed similar outcomes. Further detailed investigations on the biological activities of 1 are currently underway.

\section{ACKNOWLEDGEMENTS}

This work was supported in part by a grant from the New Energy and Industrial Technology Department Organization (NEDO) of Japan and the Project for Development of Innovative Research on Cancer Therapeutics (P-Direct).

1 Heinlein, C. A. \& Chang, C. Androgen receptor in prostate cancer. Endocr. Rev. 25 276-308 (2004).

2 Chen, Y., Sawyers, C. L. \& Scher, H. I. Targeting the androgen receptor pathway in prostate cancer. Curr. Opin. Pharmacol. 8, 440-448 (2008).

3 Grossmann, M. E., Huang, H. \& Tindall, D. J. Androgen receptor signaling in androgenrefractory prostate cancer. J. Natl Cancer Inst. 93, 1687-1697 (2001).
4 Taplin, M. E. \& Balk, S. P. Androgen receptor: a key molecule in the progression of prostate cancer to hormone independence. J. Cell Biochem. 91, 483-490 (2004).

5 Chen, C. D. et al. Molecular determinants of resistance to antiandrogen therapy. Nat. Med. 10, 33-39 (2004).

6 Mashima, T., Okabe, S. \& Seimiya, H. Pharmacological targeting of constitutively active truncated androgen receptor by nigericin and suppression of hormone-refractory prostate cancer cell growth. Mol. Pharmacol. 78, 846-854 (2010).

7 Matsukawa, E., Nakagawa, Y., limura, Y. \& Hayakawa, M. A new enrichment method for the selective isolation of Streptomycetes from the root surfaces of herbaceous plants. Actinomycetologica 21, 66-69 (2007).

8 Chun, J. et al. EzTaxon: a web-based tool for the identification of prokaryotes based on 16S ribosomal RNA gene sequences. Int. J. Syst. Evol. Microbiol. 57, 2259-2261 (2007).

9 Furihata, K. \& Seto, H. Constant time HMBC (CT-HMBC), a new HMBC technique useful for improving separation of cross peaks. Tetrahedron Lett. 39, 7337-7340 (1998).

10 Takamatsu, S. et al. Louisianins A, B, C and D: non-steroidal growth inhibitors of testosterone-responsive SC 115 cells II. Physico-chemical properties and structural elucidation. J. Antibiot. 48, 1090-1094 (1995).

11 Henne, P., Grabley, S., Thiericke, R. \& Zeeck, A. Secondary metabolites by chemical screening, 36. ulupyrinone and ulufuranol: new heteroaromatic metabolites from Streptomyces spina. Liebigs Ann. 1997, 937-939 (1997).

12 van Bokhoven, A. et al. Molecular characterization of human prostate carcinoma cell lines. Prostate 57, 202-225 (2003)

13 Komiyama, K. et al. Louisianins A, B, C and D: Non-steroidal growth inhibitors of testosterone-responsive SC 115 cells I. Taxonomy, fermentation, isolation and biological characteristics. J. Antibiot. 48, 1086-1089 (1995). 